\title{
Racial variation in the association between gestational age and perinatal mortality: prospective study
}

\author{
Imelda Balchin, clinical research fellow, ${ }^{1}$ John C Whittaker, professor, ${ }^{2}$ Roshni Patel, clinical academic training \\ fellow, ${ }^{3}$ Ronald F Lamont, consultant and reader, ${ }^{4}$ Philip J Steer, professor ${ }^{1}$
}

${ }^{1}$ Academic Department of Obstetrics and Gynaecology, Imperial College Faculty of Medicine, Chelsea and Westminster Hospital, London SW10 9NH

${ }^{2}$ Department of Epidemiology and Population Health, London School of Hygiene and Tropical Medicine, London WC1E 7HT

${ }^{3}$ Division of Obstetrics and

Gynaecology, University of Bristol, St Michael's Hospital, Bristol BS2 8EG

${ }^{4}$ Department of Obstetrics and Gynaecology, Imperial College Faculty of Medicine, Northwick Park Hospital, Middlesex HA1 3UJ

Correspondence to: I Balchin, 41 Hockley Avenue, East Ham, London E63AN balchin@doctors.org.uk

doi: 10.1136/bmi.39132.482025.80

\section{ABSTRACT}

Objectives To determine if the risks of perinatal mortality and antepartum stillbirth associated with post term birth increase earlier during pregnancy in South Asian and black women than in white women, and to investigate differences in the factors associated with antepartum stillbirth between the racial groups.

Design Prospective study using logistic regression analysis.

Setting 15 maternity units in northwest London from 1988 to 2000.

Participants 197061 nulliparous women self reported as white, South Asian, or black, who delivered a single baby weighing at least $500 \mathrm{~g}$ at 24-43 completed weeks' gestation.

Main outcome measures Gestation specific perinatal mortality, antepartum stillbirth rates, and independent factors for antepartum stillbirth by racial groups. Results The crude gestation specific perinatal mortality patterns for the three racial groups differed ( $\mathrm{P}<0.001)$. The perinatal mortality rate among black women was lower than among white women before 32 weeks but was higher thereafter. Perinatal mortality was highest among South Asian women at all gestational ages and increased the fastest at term. After adjusting for the confounders of antepartum stillbirth (placental abruption, congenital abnormality, low birth weight, birth weight $<10$ th centile, meconium passage, fever, maternal body mass index $\geq 30$, and maternal age $\geq 30$ ), the excess mortality among black women after 32 weeks was not significant. After adjusting for confounding, South Asian women still had a significantly higher risk of antepartum stillbirth (odds ratio $1.8,95 \%$ confidence interval 1.2 to 2.7 ).

Conclusions The risk of perinatal mortality increased earlier in gestation among South Asian women than among white women. The most important factor associated with antepartum stillbirth among white women was placental abruption, but among South Asian and black women it was birth weight below $2000 \mathrm{~g}$.

\section{INTRODUCTION}

In 1977, the World Health Organization defined post term pregnancy as beyond 41 completed weeks from the first day of the last menstrual period. ${ }^{1}$ By this definition, it occurs in 4.4-14.9\% of pregnancies. ${ }^{23}$ Compared with birth at term ( 37 to less than 42 completed weeks), it is associated with increased perinatal mortality and morbidity, mainly antepartum stillbirth. ${ }^{4-9}$ One hypothesis is that the fetus outgrows placental function. ${ }^{1011}$ Induction of labour after 41 weeks of gestation avoids this risk. ${ }^{12}$

However, the WHO definition of term pregnancy is an epidemiological concept, based on the statistical distribution of the timing of delivery from the last menstrual period, not on the risk of complications. The last menstrual period, even if recalled accurately, does not precisely indicate the date of conception. ${ }^{1314}$ Therefore, the WHO definition incorporates inaccuracies in assessing gestational age at birth. Dating by ultrasonography in the first half of pregnancy reduces the proportion of pregnancies classified as post term by up to $63 \% .{ }^{14}{ }^{15}$ Moreover, post term is not synonymous with functional "postmaturity" because not all babies mature at the same rate. ${ }^{16}$ Importantly, the complications of post term pregnancies have mainly been studied in white populations. Thus, conclusions cannot necessarily be applied to different racial populations. For example, in northwest London, allowing for confounders, the average length of gestation for singleton pregnancies was 39 weeks for South Asian and black women and 40 weeks for white women. ${ }^{17}$ In a Nigerian study of black Africans, the average length of gestation was 38.8 weeks. ${ }^{18}$ Maternal genetic factors are known to influence the length of gestation. ${ }^{19}$

Generalisations from data on white women only have led to the widespread practice of offering induction of labour to all women after 41 weeks of gestation. However, if the shorter length of gestation in South Asian and black women has a physiological basis, the likelihood of perinatal complications may increase earlier in these women. We tested this hypothesis by studying perinatal mortality according to length of gestation in white, South Asian, and black women and investigated whether the factors associated with antepartum stillbirth varied between racial groups.

\section{METHODS}

From 1988 to 2000 , data on 263 variables from the first antenatal visit up to 28 days postpartum were collected prospectively from all pregnancies (585 291) booked at 15 maternity units in northwest London, using the St Mary's maternity information system. Computer 
entry by trained clerks or midwives using online validation, prompting, and standard definitions for clinical measurements produced high quality data. ${ }^{2021} \mathrm{We}$ used SPSS and S-PLUS to analyse the data.

We studied nulliparous women who self reported as white, black, or South Asian and delivered a single baby weighing at least $500 \mathrm{~g}$ at 24-43 weeks of gestation. Studying only nulliparous women ensures that only one delivery is included for each woman and avoids the confounding influence of previous poor obstetric history on management. Black women were British, African, or Caribbean. South Asian women were Indian, Pakistani, Sri Lankan, or Bangladeshi. Women in other racial groups were too few to study.

Stillbirth was divided into antepartum (before labour), intrapartum (during labour), and indeterminate (uncertain timing). The early neonatal death rate is death in the first seven days of life per 1000 live births. The perinatal mortality rate is stillbirths plus early neonatal deaths per 1000 births. Perinatal mortality data from the St Mary's database were cross checked against national death registrations and the database of the Confidential Enquiry into Stillbirths and Deaths in Infancy.

The best estimate of gestational age at delivery was calculated from the first day of the last menstrual period or biparietal diameter measurements taken from fetal ultrasonography recordings made before 24 weeks of gestation (usually second trimester ultrasonography because most units only began routine first trimester ultrasonography after 2000). The dates of the last menstrual period were used when women were certain of their dates, had regular cycles, and the discrepancy between the estimated dates of delivery by the last menstrual period and ultrasonography was fewer than 14 days. A more detailed description of these methods has been reported previously. ${ }^{22}$

\section{Perinatal mortality}

We tested the difference in perinatal mortality between racial groups by using the likelihood ratio based on a logistic regression model with the outcome perinatal mortality and a null hypothesis that model coefficients are not different between racial groups. The predictor variables were racial groups, using white women as a reference, and completed weeks of gestation at birth. A polynomial term of order four for gestational age best described its association with perinatal mortality. Interaction terms between racial groups and gestational age further improved the model. We used the model to plot gestation specific perinatal mortality for each racial group. Confounding factors were not considered at this stage, as we were interested in the "real life" risk of mortality that incorporated the various risk factors associated with racial groups, rather than a theoretical "risk nullified" population. If the gestation specific risk of perinatal mortality is significantly higher in black or South Asian women than in white women, this should be taken into account when making decisions about inducing labour, regardless of known or unknown confounding variables.

\section{Antepartum stillbirths}

Next, we excluded preterm births from the analyses because from term onwards logistic regression using a quadratic term for gestational age produced a significantly improved gestation specific perinatal mortality model. We focused on antepartum stillbirth because this was the major component of perinatal mortality. The factors associated with antepartum stillbirth were analysed separately from intrapartum stillbirth and early neonatal death because when antepartum stillbirths were diagnosed most women were offered induction of labour without fetal monitoring, resulting in a different pattern of labour onset and mode of delivery. We tested the difference in antepartum stillbirth at term and post term between racial groups using a logistic regression model with the outcome variable antepartum stillbirth, the predictor variables racial group and gestational age (quadratic term), and a null hypothesis that model coefficients are not different between racial groups. A gestation specific antepartum stillbirth model was used to determine when the risk was at its minimum. We investigated the variables associated with antepartum stillbirth from term onwards and performed this analysis separately for each racial group.

To examine the interactions between racial group, mortality, and birth weight, we grouped birth weight into $500 \mathrm{~g}$ intervals. The $3500-3999 \mathrm{~g}$ category had the lowest perinatal mortality rate and was used as reference. We also examined the distribution of birth weight for gestational age by developing centile growth curves specific to each racial group, and allocating a centile value to each birth weight. We used $\chi^{2}$ and Mann-Whitney $U$ tests to analyse categorical and continuous variables, respectively. Variables with a significant association with mortality $(\mathrm{P}<0.05)$ were entered into a backward stepwise logistic regression analysis. We did not correct for multiple testing because most variables had strong associations with mortality $(\mathrm{P}<0.001)$ and would still be significant even if the Bonferroni rule were applied. ${ }^{23}$

\section{RESULTS}

The maternity records of 197016 women met the initial inclusion criteria. Of these, $81 \%$ (159 225) were white women, 13\% (25 234) were South Asian, and 6\% (12 557) were black. There were 1258 perinatal deaths. Of these, 71\% (890) were white babies, 18\% (232) were South Asian, and 11\% (136) were black. The overall perinatal mortality rate was six per 1000 births; $61 \%$ of deaths were antepartum stillbirths, 10\% intrapartum stillbirths, $6 \%$ indeterminate stillbirths, and 23\% early neonatal deaths. The perinatal mortality rate did not change significantly during the study period for any racial group. South Asian women had a higher rate of antepartum stillbirth, whereas black women had higher rates of antepartum stillbirth, intrapartum stillbirth, and early neonatal death than white babies (table 1). We found no significant difference between South Asian and black women in any categories.

Around 95\% of white women, 96\% of South Asian women, and $93 \%$ of black women had midtrimester 
Table 1 |Crude perinatal mortality rates (per 1000 births) and odds ratios in different racial groups ( $95 \%$ confidence intervals)

\begin{tabular}{|c|c|c|c|c|c|}
\hline \multirow[b]{2}{*}{ Type of death } & \multirow[b]{2}{*}{ White women } & \multicolumn{2}{|c|}{ South Asian women } & \multicolumn{2}{|c|}{ Black women } \\
\hline & & Mortality rate & Odds ratio & Mortality rate & Odds ratio \\
\hline Perinatal mortality & $5.6(5.2$ to 6.0$)$ & 9.2 (8.0 to 10.4$)$ & $1.6(1.4$ to 1.9$)$ & 10.8 (9.0 to 12.6$)$ & 2.0 (1.6 to 2.3$)$ \\
\hline Stillbirth & 4.3 (4.0 to 4.6$)$ & 7.5 (6.4 to 8.5$)$ & 1.8 (1.5 to 2.1$)$ & 7.8 (6.3 to 9.3$)$ & 1.8 (1.5 to 2.3$)$ \\
\hline Antepartum stillbirth & 3.3 (3.1 to 3.6 ) & $6.2(5.2$ to 7.2$)$ & 1.9 (1.6 to 2.2$)$ & $6.3(4.9$ to 7.7$)$ & 1.9 (1.5 to 2.4$)$ \\
\hline Intrapartum stillbirth & $0.6(0.5$ to 0.7$)$ & 0.5 (0.2 to 0.8$)$ & 0.9 (0.5 to 1.5$)$ & $1.2(0.6$ to 1.8$)$ & 2.0 (1.1 to 3.4$)$ \\
\hline Indeterminate stillbirth & $0.3(0.2$ to 0.4$)$ & $0.8(0.4$ to 1.1$)$ & 2.3 (1.4 to 3.9 ) & $0.3(0.0$ to 0.6$)$ & $1.0(0.4$ to 2.7$)$ \\
\hline Early neonatal death & 1.3 (1.1 to 1.5$)$ & 1.8 (1.2 to 2.3$)$ & 1.3 (1.0 to 1.8$)$ & 3.1 (2.1 to 4.0$)$ & 2.3 (1.6 to 3.3$)$ \\
\hline
\end{tabular}

Odds ratios use the white racial group as reference.

ultrasonography. Overall, estimated dates of delivery by ultrasonography corresponded with those from the last menstrual period in $80 \%$ of cases. When they were discrepant, ultrasound dating was used. In $4 \%$ of cases, only the estimated date of delivery by the last menstrual period was available. Dating was impossible in less than $1 \%$ of cases and these were excluded. A significantly higher proportion of South Asian women than white women were certain of their dates and had regular cycles $\left(87 \% v 81 \% ; \chi^{2}=433\right.$, degrees of freedom $=1, \mathrm{P}<0.001)$. The opposite was seen for black women $\left(78 \% v 81 \% ; \chi^{2}=55, \mathrm{df}=1, \mathrm{P}<0.001\right)$. In women with a reliable date for their last menstrual period, the estimated date of delivery by ultrasonography corresponded with that calculated from the last period in $94.6 \%$ of white women, $94.4 \%$ of South Asian women, and $94.0 \%$ of black women. The difference was not significant between South Asian women and white women $\left(\chi^{2}=1, \mathrm{df}=1, \mathrm{P}=0.32\right)$ but was significant between black women and white women $\left(\chi^{2}=4, \mathrm{df}=1\right.$, $\mathrm{P}=0.03)$. None the less, the method of dating used was not significantly associated with perinatal mortality $\left(\chi^{2}=3, \mathrm{df}=1, \mathrm{P}=0.08\right)$.

The racial groups differed significantly in their patterns of gestation specific perinatal mortality $\left(\chi^{2}=3472, \mathrm{df}=9, \mathrm{P}<0.001\right.$; fig 1$)$. The Hosmer-Lemeshow test, a goodness of fit statistic, showed no significant difference between the actual and model predicted numbers of perinatal deaths $\left(\chi^{2}=7, \mathrm{df}=6\right.$, $\mathrm{P}=0.33)$. South Asian women had the highest perinatal mortality rate at all times during gestation. Black women had the lowest preterm gestation specific mortality, but their overall perinatal mortality rate was the

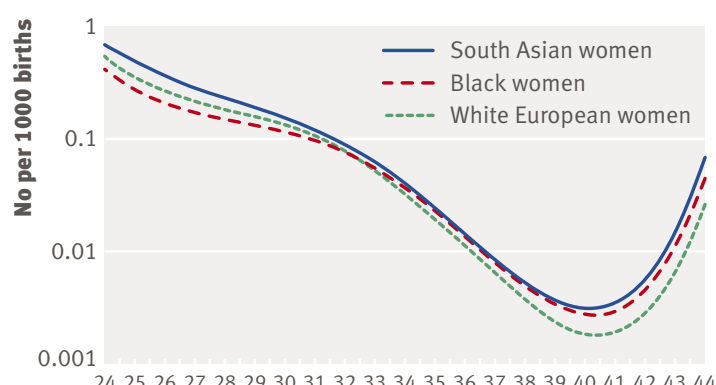

Completed weeks of gestation at birth

Fig 1 Gestation specific perinatal mortality rate by racial group highest because they had the highest preterm birth rate (table 1; fig 1). Exclusion of preterm births left 183392 cases. The racial groups differed significantly in their patterns of gestation specific perinatal mortality from term onwards $\left(\chi^{2}=85, \mathrm{df}=8, \mathrm{P}<0.001\right.$; HosmerLemeshow $\left.\chi^{2}=3, \mathrm{df}=5, \mathrm{P}=0.68\right)$.

White women and South Asian women differed significantly in their patterns of gestation specific antepartum stillbirth from term onwards $\left(\chi^{2}=81, \mathrm{df}=4\right.$, $\mathrm{P}<0.001$; Hosmer-Lemeshow test $\left.\chi^{2}=4, \mathrm{df}=5, \mathrm{P}=0.9\right)$. The pattern in black women was closer to that seen in South Asian women than in white women, although the difference between either group was insignificant. The antepartum stillbirth rate was lowest at 40 weeks of gestation (2 per 1000 births, 95\% confidence interval 1.3 to 2.7 ) among South Asian women and at 41 weeks (1 per 1000 births, 0.8 to 1.2 ) among white women. The antepartum stillbirth rate was higher among South Asian women than among white women at all gestational times (fig 2). The predicted antepartum stillbirth rate among South Asian women was 2.7 times higher than that among white women at 41 weeks of gestation (2.6 $v 1.0,1.6$ to 3.5 and 0.8 to 1.2 ) and 3.8 times higher at 42 weeks ( $4.6 v 1.2,1.8$ to 7.3 and 0.8 to 1.6 ).

Table 2 shows the independent predictors of antepartum stillbirth for the whole population and for the different racial groups. Potential confounders of the association between racial group and antepartum stillbirth were accounted for. Being South Asian was an independent risk factor for antepartum stillbirth compared with being white. The overall odds of placental abruption were significantly higher in black

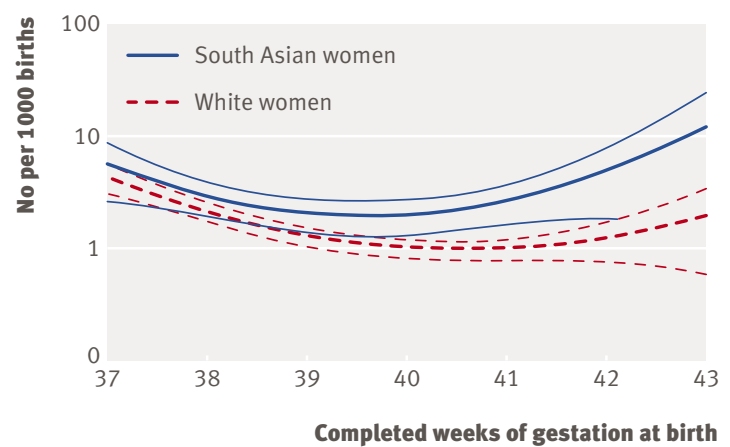

Fig 2 Gestation specific antepartum stillbirth model; predicted estimates with upper and lower $95 \%$ confidence intervals 


\begin{tabular}{|c|c|c|c|c|}
\hline \multirow[b]{2}{*}{ Factor } & \multicolumn{4}{|c|}{ Ethnic group } \\
\hline & All groups & White & South Asian & Black \\
\hline Placental abruption & 21.2 (10.9 to 41.2$)$ & 16.7 (7.7 to 36.2$)$ & 28.4 (5.3 to 106.3$)$ & - \\
\hline Meconium stained liquor & 6.5 (4.8 to 8.8$)$ & 7.9 (5.6 to 11.3$)$ & $3.7(2.2$ to 7.0$)$ & 4.4 (1.9 to 10.2$)$ \\
\hline \multicolumn{5}{|l|}{ Birth weight (g) } \\
\hline$<2000$ & - & - & 60.5 (10.7 to 330.6$)$ & 49.6 (10.5 to 233$)$ \\
\hline 2000-2499 & - & - & 13.9 (2.9 to 63.0) & 7.3 (1.8 to 29.4$)$ \\
\hline $4000-4499$ & - & - & 10.3 (1.9 to 58.7$)$ & - \\
\hline \multicolumn{5}{|l|}{ Centile } \\
\hline$<3 r d$ & $4.8(1.9$ to 12.2$)$ & $6.6(4.0$ to 10.6$)$ & - & - \\
\hline 3rd-9th & $4.4(2.2$ to 8.7$)$ & $3.6(2.2$ to 5.7$)$ & - & - \\
\hline Maternal fever & $3.6(2.1$ to 6.1$)$ & 3.7 (1.9 to 7.1$)$ & $5.2(2.0$ to 12.1$)$ & - \\
\hline $\begin{array}{l}\text { Fetal congenital } \\
\text { abnormality }\end{array}$ & 3.3 (1.9 to 6.0$)$ & 2.9 (1.4 to 5.9$)$ & - & - \\
\hline \multicolumn{5}{|l|}{ Maternal body mass index* } \\
\hline$\geq 30$ & 2.2 (1.4 to 3.3$)$ & 1.9 (1.2 to 3.0$)$ & $3.7(1.5$ to 8.8$)$ & - \\
\hline$<20$ & $0.5(0.3$ to 0.9$)$ & $0.3(0.1$ to 0.8$)$ & - & 一 \\
\hline Maternal age $\geq 30 \dagger$ & $1.8(1.4$ to 2.5$)$ & $1.8(1.3$ to 2.5$)$ & 1.9 (1.3 to 3.3$)$ & - \\
\hline South Asian & $1.8(1.2$ to 2.7$)$ & & & \\
\hline \multicolumn{5}{|c|}{$\begin{array}{l}\text { *Reference group 20-24. } \\
\text { †Reference group 20-29 years. } \\
\text { Non-significant variables were maternal hypertensive disorders, diabetes mellitus, smoking, urinary tract } \\
\text { infection, late prenatal care beyond } 20 \text { weeks' gestation, unreliable date for last menstrual period, marital } \\
\text { status, Carstairs' deprivation score, and fetal sex. }\end{array}$} \\
\hline
\end{tabular}

women than in white women (odds ratio 1.3, 1.1 to 1.7), but from term onwards the difference was insignificant $(0.8,0.5$ to 1.2$)$. From term onwards, South Asian women had a lower risk of placental abruption than white women (0.6, 0.4 to 0.9 ). The odds of having a low birthweight baby $(<2500 \mathrm{~g})$ were higher in South Asian women (3.6, 3.4 to 3.9) and black women (1.7, 1.5 to 1.8$)$ than in white women. The Carstairs index measures material deprivation and social class according to designated postal area. ${ }^{24-26}$ Although deprivation was greater in South Asian and black women than in white women $(3.5,3.4$ to $3.6 ; 5.2,5.0$ to 5.4$)$, this did not affect perinatal mortality.

The overall odds of early neonatal death were significantly higher among black women than among white women (2.3, 1.6 to 3.3), which explains their overall higher perinatal mortality rate. This might be because the odds of preterm birth were also significantly higher among black women (1.8, 1.7 to 1.9). After 33 weeks of gestation, their odds of early neonatal death were not significantly higher than among white women (1.5, 0.8 to 2.7). The odds of intrapartum stillbirth were also significantly higher among black women $(2.0,1.1$ to $3.4)$, possibly because of the higher incidence of congenital abnormality in black babies $(1.7,1.5$ to 1.9$)$. Excluding congenital abnormality, the odds of intrapartum stillbirth among black women were not significantly higher than among white women $(1.6,0.8$ to 3.1$)$, although this may reflect reduced statistical power.

\section{DISCUSSION}

Our data for white women concur with previously published data from which the policy of inducing labour after 41 weeks' gestation was derived. Perinatal mortality patterns differed significantly with racial group. Before 32 weeks' gestation, perinatal mortality was lowest in black women, consistent with the known accelerated pulmonary maturity of fetuses in this racial group. ${ }^{2728}$ At all gestational ages, perinatal mortality was highest in babies of South Asian women, and from term onwards the increase was earliest and steepest in South Asian women, followed by black women, and finally white women. Allowing for confounders, the risk of antepartum stillbirth was higher for South Asian women (but not black women) than for white women. The strongest factor associated with antepartum stillbirth in white women was placental abruption. In South Asian and black women, the strongest factor was having a baby with birth weight below $2000 \mathrm{~g}$, possibly as a result of growth restriction. ${ }^{29}$ The differences in the incidence of placental abruption and low birth weight partly explained the differences in perinatal mortality.

An advantage of our study was the large non-white population, which gave it high statistical power. Most of the women were born in the UK and only $4.8 \%$ of residents in 1997 were asylum seekers. ${ }^{3031}$ Equal opportunity for maternity care is high within the National Health Service. This probably explains why material deprivation did not significantly influence the racial patterns of perinatal mortality. Most variables previously identified as risk factors for perinatal mortality were investigated. ${ }^{7-932}$ Calculation of the estimated dates of delivery was robust, based on a combination of the last menstrual period and ultrasonography. In South Asian women with a reliable date for their last menstrual period, the proportion in whom the estimated date of delivery was corrected by ultrasonography was not significantly different from that of white women. There is no evidence that South Asian fetuses are smaller than white ones in early pregnancy, so the ultrasonography algorithm used for white fetuses was applicable to South Asians.

To compare the difference between racial groups, we used the number of births at a given gestational age as the denominator to calculate stillbirth rates. Some studies have calculated stillbirth rates using "ongoing live pregnancies" at a given gestational age as the denominator, but those studies investigated the difference between term and post term rates. ${ }^{632}$ Both methods made no difference to the odds ratios between racial groups.

Our results suggest that a randomised controlled trial of increased fetal surveillance and growth monitoring from 40 , rather than 41 , weeks' gestation in South Asian and black women is justified, although very large numbers would need to be recruited. The racial classification in this study, although crude, is a probable indicator of genetic variation in normal gestational length. Whether differences in outcome were due to social disadvantage or biology, the implications for management are the same. 


\section{WHAT IS ALREADY KNOWN ON THIS TOPIC}

In white women, the risk of perinatal mortality is higher in post term pregnancies than in term pregnancies (as defined by the World Health Organization)

\section{WHAT THIS STUDY ADDS}

The odds of perinatal mortality were higher for South Asian women than for white or black women, and at term the odds increased fastest in South Asian women

The most important risk factor for antepartum stillbirth in white women was placental abruption, but the most important factor in South Asian and black women was birth weight below $2000 \mathrm{~g}$ management of the postterm gravida. Am J Obstet Gynecol 1975;123:67-103.

11 Thliveris JA, Baskett TF. Fine structure of the human placenta in prolonged pregnancy. Preliminary report. Gynecol Obstet Invest 1978;9:40-8.

12 Crowley P. Interventions for preventing or improving the outcome of delivery at or beyond term. Cochrane Database Syst Rev 1997;(1):CD000170.

13 Geirsson RT, Busby-Earle RMC. Certain dates may not provide a reliable estimate of gestational age. Br J Obstet Gynaecol 1991;98:108-9.

14 Savitz DAP. Comparison of pregnancy dating by last menstrual period, ultrasound scanning, and their combination. Am J Obstet Gynecol 2002;187:1660-6.

15 Hogberg U. Early dating by ultrasound and perinatal outcome: a cohort study. Acta Obstet Gynaecol Scand 1997;76:907-12.

16 Callenbach JC, Hall RT. Morbidity and mortality of advanced gestational age: post-term or postmature. Obstet Gynecol 1979;53:721-4.

We thank the midwives, medical staff, and secretarial staff of the North West Thames obstetric units who collected and entered data into the North West Thames maternity database.

Contributors: IB wrote the first draft of the paper and helped refine the hypothesis, design the methodology, and analyse the data. JCW devised and supervised the statistical analysis. RP helped refine the hypothesis and carried out the initial analysis. RFL suggested variables for study. PJS formulated the original hypothesis and helped analyse the data and write the first draft. All authors helped edit the final draft and approved its contents. IB is guarantor. Funding: None.

Competing interests: None declared.

Ethical approval: St Mary's local research ethics committee, London.

1 WHO. Recommended definitions, terminology and format for statistical tables related to the perinatal period and use of a new certificate for cause of perinatal deaths. Modifications recommended by FIGO as amended October 14, 1976 Acta Obstet Gynaecol Scand 1977;56:247-53.

2 Chamberlain G, Phillip E, Howlett B, Masters K. British births 1970. Obstetric Care London: Heinemann Medical Books, 1978.

3 Bjerkedal T, Bakketeig LS. Medical registration of births in Norway during the 5-year period 1967-71. Time trends and differences between countries and between municipalities. Bergen: Institute of Hygiene and Social Medicine, University of Bergen, 1975.

4 Olesen AW, Westergaard JG, Olsen J. Perinatal and maternal complications related to postterm delivery: a national register-based study, 1978-1993. Am J Obstet Gynecol 2003;189:222-7.

5 Crowley P. Post term pregnancy: induction or surveillance? In: Chalmers I, Enkins M, Kierse MJN, eds. Effective care in pregnancy and childbirth. Oxford: Oxford University Press, 1989.

6 Hilder L, Costeloe K, Thilaganathan B. Prolonged pregnancy: evaluating gestation-specific risks of fetal and infant mortality. Br J Obstet Gynaecol 1998;105:169-73.

7 Divon MY, Haglund B, Nisell H, Otterblad PO, Westgren M, Caritis SN, et al. Fetal and neonatal mortality in the postterm pregnancy: the impact of gestational age and fetal growth restriction. Am J Obstet Gynecol 1998;178:726-31.

8 Rasmussen S, Albrechtsen S, Irgens LM, Dalaker K, Maartmann-Moe H, Vlatkovic L, et al. Risk factors for unexplained antepartum fetal death in Norway 1967-1998. Early Hum Dev 2003;71:39-52.

9 Clausson BM, Cnattingius S, Axelsson O. Outcomes of post-term births: the role of fetal growth restriction and malformations. Obstet Gynecol 1999;94:758-62.

10 Vorherr $\mathrm{H}$. Placental insufficiency in relation to postterm pregnancy and fetal postmaturity. Evaluation of fetoplacental function;
17 Patel RR, Steer P, Doyle P, Little MP, Elliott P. Does gestation vary by ethnic group? A London-based study of over 122000 pregnancies with spontaneous onset of labour. Int J Epidemiol 2004;33:107-13.

18 Onah HE. Effect of prolongation of pregnancy on perinatal mortality. Int J Gynecol Obstet 2003;80:255-61.

19 Laursen MM. Genetic influence of prolonged gestation: a populationbased Danish twin study. Am J Obstet Gynecol 2004;190:489-94.

20 Maresh M, Dawson AM, Beard RW. Assessment of an on-line computerized perinatal data collection and information system. Br J Obstet Gynaecol 1986;93:1239-45.

21 Cleary R, Beard RW, Coles J, Devlin HB, Hopkins A, Roberts S, et al. The quality of routinely collected maternity data. BrJ Obstet Gynaecol 1994;101:1042-7.

22 Balchin I, Whittaker JC, Steer PJ, Lamont RF. Are reported preterm birth rates reliable? An analysis of interhospital differences in the calculation of the weeks of gestation at delivery and preterm birth rate. BJOG 2004;111:160-3.

23 Perneger TV. What's wrong with Bonferroni adjustments. BM/ 1998;316:1236-8.

24 Carstairs V. Deprivation indices: their interpretation and use in relation to health. J Epidemiol Community Health 1995;49(suppl 2):S3-8.

25 Dolan SA, Jarman B, Bajekal M, Davies PM, Hart D. Measuring disadvantage: changes in the underprivilege area, Townsend and Carstairs scores 1981-91. J Epidemiol Community Health 1995;49(suppl 2):S30-3.

26 Morris R, Carstairs V. Which deprivation? A comparison of selected deprivation indices. J Public Health Med 1991;13:318-26.

27 Berman SMM, Tanasijevic M. Racial differences in the predictive value of the TDx fetal lung maturity assay. Am J Obstet Gynecol 1996;175:73-7.

28 Floros JOAN. Surfactant protein (SP) B associations and interactions with SP-A in white and black subjects with respiratory distress syndrome. Pediatr Int 2001;43:567-76.

29 Steer P. The management of large and small for gestational age fetuses. Semin Perinatol 2004;28:59-66.

30 Bardsley M. Storkey M. Estimating the numbers of refugees in London. J Public Health Med 2000;22:406-12.

31 North West London Strategic Health Authority. Refugee health in London.Key issues for public health. Health of Londoners project 1999. www.lho.org.uk/Publications/Attachments/PDF_Files/ refugees.pdf.

32 Huang DY, Usher RH, Kramer MS, Yang H, Morin L, Fretts RC. Determinants of unexplained antepartum fetal deaths. Am J Obstet Gynecol 2000;95:215-21.

Accepted: 23 January 2007 